\title{
Factors Associated with Costs of Hospitalization of Severely Mentally Ill Patients
}

Martina Curto ${ }^{1-3 *}$, Grace A Masters ${ }^{2}$, Paolo Girardi ${ }^{3}$, Ross J Baldessarini ${ }^{1,2}$ and Franca Centorrino ${ }^{1,2}$

${ }^{1}$ Department of Psychiatry, Harvard Medical School, Boston, MA, USA

${ }^{2}$ Psychopharmacology Lab, McLean Hospital, Belmont, MA, USA

${ }^{3}$ Department of Psychiatry, Sant'Andrea Medical Center-University of Rome (Sapienza), Italy

\begin{abstract}
Background: Efforts to contain costs associated with general medical care include particular efforts for psychiatric disorders. Hospitalization represents the largest component of costs for psychiatric care and there is growing interest in balancing clinical needs against limiting costs of inpatient psychiatric care of patients with severe mental illnesses. This study aimed to evaluate clinical factors associated with actual costs of inpatient psychiatric care.
\end{abstract}

Method: We evaluated a cohort of 589 hospitalized psychiatric patients with severe mental illnesses at a nonprofit, university-affiliated psychiatric hospital for factors associated with annualized total costs of inpatient care over a three-year period, using bivariate and multivariate analyses.

Results: As expected, days-hospitalized was the major determinant of total costs of hospital care. In addition, several clinical and treatment factors also were associated significantly and independently with costs in multivariate modeling. These included presence of psychosis, electroconvulsive treatment, specialist consultations, use of multiple antipsychotics or of clozapine, and being discharged to a supervised living arrangement, but not sex, age, marital status, employment, or substance abuse.

Discussion: As expected, costs of psychiatric hospitalization were dominated by per-diem charges, but also influenced by other, potentially modifiable treatment factors generally associated with more severe psychotic illnesses. The study is based on actual costs rather than on insurer-reimbursements and a large study-sample, though at a single institution. Specific factors identified encourage focusing on patient characteristics associated with greater costs and redoubled efforts to apply and improve alternative, cost-effective interventions such as partialhospital and intensive outpatient treatment.

Keywords: Antipsychotics; Costs; Factors; Hospitalization; Major mental illness; Psychosis; Psychiatric care

\section{Introduction}

Major mental illnesses are prevalent disorders that contribute to a substantial proportion of overall illness burdens. Excluding dementias, they occur at a combined lifetime prevalence of nearly $5 \%$ for psychotic and bipolar disorders and approximately $10 \%$ for major depressive disorder [1-3]. As largely chronic or recurrent illnesses, they carry high risks of disability and early mortality, in addition to representing extraordinary direct (care) and indirect (disability) costs to society [4-11]. Such disorders particularly during acute dysfunction, dangerousness, and with commonly co-occurring general medical illness represent the most frequent reason for hospitalization in psychiatric units of general hospitals as well as specialized institutions $[2,3,12-14]$. Moreover, the costs would be far larger if not for the major diversion of the severely mentally ill to the criminal justice system, particularly in the US [15-18].

Along with efforts to contain costs associated with general medical care, there have been particular efforts to limit costs of treating patients with psychiatric disorders $[19,20]$. Annual costs of care for mentally ill persons in the US now exceed \$200-billion. This is the third highest category of healthcare costs in the nation, tied with cancer, and representing a substantial proportion of total national health care expenditures, now approaching \$4-trillion per year [19,21-23]. The largest component of the costs for psychiatric care is hospitalization-representing between a quarter and one-third of total costs; the remainder is associated with partial-hospital and ambulatory care, prescription drugs, and administrative costs [5]. As a leading contributor to the costs of care, hospitalization is a target of intense scrutiny among insurers, administrators, and others seeking to rein in costs of mental health services, while balancing the obligation to meet clinical needs $[19,20,24]$.

Facilitating efforts to limit costs, modern clinical psychopharmacology has helped to provide a relatively efficient and cost-effective component of treatment. The rise of pharmacotherapy has been associated with less frequent and shorter hospitalizations, briefer outpatient visits and less emphasis on lengthy psychotherapies, especially for patients with relatively mild or moderate illnesses $[25,26]$. Nevertheless, psychiatric hospitalization, especially of the severely mentally ill, has been unavoidable and the costs of hospitalization [and incarceration] remain a leading financial strain to individuals, thirdparty payers, and society [5,12,27-29]. Efforts to manage costs associated with psychiatric illness include increasingly strenuous requirements by insurers tending to limit hospital admissions and days per admission

*Corresponding author: Martina Curto, NeSMOS, Sant'Andrea Hospital, Via di Grottarossa 1035-1039, Rome 00189, Italy, Tel: + 39063 3775951; E-mail: martina.curto@gmail.com

Received October 23, 2015; Accepted January 30, 2016; Published February 07,2016

Citation: Curto M, Masters GA, Girardi P, Baldessarini RJ, Centorrino F (2016) Factors Associated with Costs of Hospitalization of Severely Mentally III Patients. Bipolar Disord 2: 104. doi:10.4172/jbd.1000104

Copyright: ( 2016 Curto M, et al. This is an open-access article distributed under the terms of the Creative Commons Attribution License, which permits unrestricted use, distribution, and reproduction in any medium, provided the original author and source are credited. 
and to reduce per-diem reimbursements for prolonged hospitalization $[24,30,31]$. Such efforts appear to be only partly effective, and they can complicate efforts to balance clinical needs against administrative and financial aims [24]. Moreover, excessively brief hospitalization not only risks adverse clinical and social consequences, but also increased costs due to re-admissions that reflect inadequate care [24]. Alternatives to inpatient care, such as partial-hospital and supervised group programs can be helpful and cost-effective, but typically are not adequately financially supported by public mental health programs or private insurances [24,32-38]. Additional costs associated with excessively restricted hospital care include more frequent clinic visits and greater utilization of expensive and inefficient emergency services $[24,36,39,40]$. Furthermore, efforts to minimize hospitalization also encourage increasingly complex, poorly evaluated, and potentially more expensive and less well tolerated pharmacological treatments $[25,41,42]$.

In the face of the dilemma between demands of cost-control and requirements for appropriate clinical care, there is growing interest in identifying clinical factors that contribute to the costs of inpatient care. Such efforts aim to improve allocation of services that address such risk factors, as well as predicting and managing costs associated with illnesses that require more intensive treatment [3,11,40,4345]. Proposed risk factors for psychiatric hospitalization include repeated occurrences or exacerbations of illness, greater overall illness severity, disability and poverty, as well as suspected non-adherence to recommended treatment [46-53].

In this study, we sought to identify clinical factors that affect the costs of psychiatric hospitalization in a large, closely evaluated cohort of patients with psychotic or major mood disorders during and following hospitalizations in a university-affiliated, psychiatric teaching hospital. A specific aim was to identify particular clinical and treatment characteristics associated with greater utilization and cost of inpatient care, based on actual costs rather than on reimbursements derived from insurer databases.

\section{Method}

\section{Subjects and data acquisition}

We collected data from medical records of 589 consecutive, adult patients diagnosed with psychotic or major mood disorders, hospitalized in a specialized inpatient unit at a private, non-profit, psychiatric teaching hospital between January 2010 and December 2013. We sought to provide an accurate picture of actual hospitalization costs per subject. Information was extracted independently by two experienced investigators (MC, GM) and discrepancies were resolved by investigator-consensus. The study was reviewed and approved for anonymous and aggregate reporting of findings by the hospital's Institutional Review Board. Other findings arising from the present cohort have been reported previously $[24,54,55]$.

Data collected from medical records included age, sex, discharge diagnoses (updated to DSM-5 criteria), socioeconomic and functional status including employment and living status, estimated age at first psychiatric symptoms and first treatment, estimated total years of illness, as well as types and doses of all drugs given within 90 days before, as well as during hospitalization and at discharge, and clinically estimated adherence with prescribed treatment in the six months prior to initial hospitalization. Also recorded were presence or absence of substance abuse, smoking status, body-mass index (BMI), pulse rate, blood pressure, hematological measures and serum concentrations of electrolytes, glucose, hemoglobin-glycosylation, lipids, and markers of kidney and liver functions assayed during hospitalization. We also noted the number and types of co-occurring general medical disorders diagnosed, as well as all testing (including electroencephalographic (EEG) and magnetic resonance brain imaging [MRI] methods), specialist-consultations, and treatments given during hospitalization, and we categorized dispositions at discharge. Costs of each service and medicine were developed with the assistance of members of the hospital pharmacy and administrative departments. We also considered the number and duration of psychiatric admissions to the same hospital (hospitalization elsewhere occurred in $<1 \%$ of cases) over the threeyear period of observation.

\section{Data analytic procedures}

We developed estimates of total costs of care, based on per-diem costs of hospitalization plus costs of medical procedures and treatments received. Total cost-estimates (thousands of US dollars (USD)/year per person) were compared in preliminary bivariate analyses (ANOVA, with $t$-scores, and relative-risk ratios as well as standardized differences as Cohen's $d$-statistic [difference/SD]) of factors of interest. Multivariate linear regression modeling then used cost/person as the dependent variable, with covariates preliminarily identified as associated with cost entered stepwise. Averages are presented as means \pm standard deviation (SD) or with $95 \%$ confidence interval (CI); results of linear regression modeling are reported as slope functions $(\beta)$ with CI. Statistical significance required two-tailed $p<0.05$, with Bonferroni adjustment for testing of multiple individual factors.

\section{Results}

\section{Characteristics of subjects}

Study subjects $(\mathrm{N}=589)$ averaged $35.7 \pm 13.0$ [18-68] years of age; $59.6 \%$ were men, and $81.8 \%$ were Caucasian. Overall duration of illness from onset averaged $12.4 \pm 9.68$ years, including the three years of observation (Table 1). Primary psychiatric diagnoses (DSM-5 criteria) ranked: bipolar disorder (36.0\%), schizoaffective disorder (18.2\%), major depressive disorder (14.4\%), schizophrenia (13.1\%), other psychotic disorders (12.6\%) and other disorders (5.77\%). Initial index hospitalizations were first-lifetime admissions for $17.3 \%$ of subjects and $84.3 \%$ of these involved psychotic disorders; $36.3 \%$ of subjects were hospitalized more than once over the three-year period sampled, at an average of $0.51 \pm 0.29$ hospitalizations/person-year, lasting on average $13.3 \pm 12.3$ days per admission. Salient characteristics are summarized in Table 1 .

\section{Factors associated with hospitalization costs}

We compared estimated, annualized total inpatient treatment costs per person for each subject over the three years sampled. A total of 21 factors, individually, were associated with greater costs per person (18 met the Bonferroni-adjusted significance criterion of $p \leq 0.002$, and 16 of these were not directly related to days/year in hospital; Table 2). Comparisons of matched pairs of mean costs/person/year for each factor were contrasted by the ratio of costs with the factor present/ absent. In addition, we computed standardized differences (Cohen's $d$-statistic for each cost-pair [not shown]). These ranged from 2.06 for cases involving hospitalization for $\geq 14$ days, to 0.26 for the presence of a lifetime suicidal act. Since the rate-ratio measures shown correlated very closely with values of $d$-statistic ( $r=0.998)$, we report the rate-ratio data to indicate the magnitude of cost differences for each covariate (Table 2). 


\begin{tabular}{|c|c|}
\hline Characteristic & Measure \\
\hline $\begin{array}{l}\text { Cases }(n, \%) \\
\text { Men } \\
\text { Women }\end{array}$ & $\begin{array}{l}589(100) \\
351(59.6) \\
23840.4)\end{array}$ \\
\hline $\begin{array}{l}\text { Social factors } \\
\text { GAF at initial admission } \\
\text { Married (\%) } \\
\text { Employed (\%) } \\
\text { Pre-admission supervised living (\%) } \\
\text { Discharged to supervised living (\%) }\end{array}$ & $\begin{array}{c}28.5 \pm 5.73 \\
14.9 \\
36.7 \\
13.6 \\
19.5\end{array}$ \\
\hline $\begin{array}{l}\text { Diagnosis (\%) } \\
\text { Bipolar disorder } \\
\text { Schizoaffective disorder } \\
\text { Major depressive disorder } \\
\text { Schizophrenia } \\
\text { Other psychoses } \\
\text { Other disorders }\end{array}$ & $\begin{array}{l}36.0 \\
18.2 \\
14.4 \\
13.1 \\
12.6 \\
5.77\end{array}$ \\
\hline Years ill * & $12.4 \pm 9.68$ \\
\hline $\begin{array}{l}\text { General medical illnesses } \\
\text { Subjects affected (n, \%) } \\
\text { Diagnoses/person }\end{array}$ & $\begin{array}{c}345(58.6) \\
1.71 \pm 2.07\end{array}$ \\
\hline $\begin{array}{l}\text { Clinical factors ( } \leq 6 \text { months; \%) } \\
\text { Substance abuse } \\
\text { Suicidal ideation or act }\end{array}$ & $\begin{array}{l}58.6 \\
60.1\end{array}$ \\
\hline $\begin{array}{l}\text { Treatments (at first discharge) } \\
\geq 2 \text { psychotropics (\%) } \\
\text { Psychotropics/person } \\
\text { Nonpsychotropic medicines/person } \\
\geq 2 \text { antipsychotics }(\%) \\
\text { Clozapine }(\%) \\
\text { ECT }\end{array}$ & $\begin{array}{l}69.4 \\
2.08 \pm 1.04 \\
2.57 \pm 2.54 \\
16.3 \\
9.85 \\
7.13\end{array}$ \\
\hline $\begin{array}{l}\text { Psychiatric hospitalization } \\
\text { Admissions/year } \\
\text { Days hospitalized/year } \\
\text { Days/admission }\end{array}$ & $\begin{array}{l}0.51 \pm 0.29 \\
6.65 \pm 4.97 \\
13.3 \pm 12.3\end{array}$ \\
\hline
\end{tabular}

[*] Includes the 3 years of observation

Table 1: Characteristics of study subjects.
Total costs of inpatient care per person averaged $\$ 9500$ (CI: 8860-10,100) USD/year. As expected, factors most associated with greater costs were more hospitalizations and more days hospitalized accounting for more than $90 \%$ of total costs. Nevertheless, other clinical and treatment factors also were significantly associated with higher total costs. Notably, these included a diagnosis of non-affective psychotic disorder, treatment with clozapine, use of multiple psychotropic drugs or multiple antipsychotics per person, two or more general medical illnesses and multiple non-psychiatric medicines, and receiving electroconvulsive treatment (ECT). In addition, unemployment, age initially $\geq 40$ years, non-Caucasian race, and discharge to a supervised living situation such as a group home (but not living in such a setting prior to admission) were associated preliminarily with higher costs. Having multiple medical diagnoses, receiving consultations with medical or psychiatric specialists, and a relatively large number of laboratory tests (excluding EEG and MRI procedures) also were related to higher costs. Diagnosis of schizophrenia or schizoaffective disorder was associated with greater costs than diagnoses of bipolar disorder or major depressive disorder (by 36\%) (Table 3), as was lifetime suicidal behavior (by 24\%). However, an Axis II diagnosis and lack of psychiatric hospitalization prior to the index admission were associated with less cost. Marital status, sex, and substance abuse were not significantly associated with hospitalization costs. Effects of selected factors on costs of hospital-care are summarized in Figure 1.

\section{Multivariate modeling}

We employed multivariate linear regression modeling to identify factors preliminarily found to be associated with hospital-based costsof-care (see Table 2), examining each for significant and independent association with costs. The number of days hospitalized/year accounted for the highest proportion of total hospitalization costs $(94.9 \%$ [CI: 94.0-94.8]). Based on multivariate linear regression modeling, with

\begin{tabular}{|c|c|c|c|c|c|}
\hline \multirow{2}{*}{ Factor } & \multicolumn{3}{|c|}{ Cost $\left[\$ /\right.$ year $\left.\times 10^{-3}\right]$ vs. Factor } & \multirow{2}{*}{ t-score } & \multirow{2}{*}{ p-value } \\
\hline & Present & Absent & Ratio & & \\
\hline$>14$ Hospital days total & $14.4 \pm 8.27$ & $4.33 \pm 1.49$ & 3.33 & 20.4 & $<0.0001$ \\
\hline$\geq 2$ Hospitalizations/3 years & $15.3 \pm 8.80$ & $6.25 \pm 4.83$ & 2.45 & 16.1 & $<0.0001$ \\
\hline Clozapine given & $16.2 \pm 11.3$ & $8.77 \pm 7.00$ & 1.85 & 7.12 & $<0.0001$ \\
\hline ECT given & $17.0 \pm 10.4$ & $8.92 \pm 7.31$ & 1.91 & 6.67 & $<0.0001$ \\
\hline$\geq 2$ Consultations per admission & $11.8 \pm 9.29$ & $8.18 \pm 6.55$ & 1.44 & 5.53 & $<0.0001$ \\
\hline$\geq 2$ Non-psychotropic medicines & $10.9 \pm 8.78$ & $7.43 \pm 5.65$ & 1.47 & 5.41 & $<0.0001$ \\
\hline Initial hospitalization, first-lifetime & $6.25 \pm 4.89$ & $10.2 \pm 8.18$ & 0.61 & 4.68 & $<0.0001$ \\
\hline Non-independent living post-hospitalization & $12.2 \pm 10.1$ & $8.83 \pm 7.06$ & 1.38 & 4.24 & $<0.0001$ \\
\hline Schizophrenia/schizoaffective diagnosis vs. major affective disorder diagnosis & $11.1 \pm 9.16$ & $8.36 \pm 6.41$ & 1.33 & 4.18 & $<0.0001$ \\
\hline Unemployed & $10.5 \pm 8.60$ & $7.79 \pm 5.85$ & 1.35 & 4.04 & $<0.0001$ \\
\hline$I I I \geq 10$ years total & $10.7 \pm 6.29$ & $8.18 \pm 6.29$ & 1.31 & 3.97 & $<0.0001$ \\
\hline$\geq 2$ Medical diagnoses & $10.9 \pm 8.91$ & $8.47 \pm 6.82$ & 1.29 & 3.78 & 0.0002 \\
\hline$\geq 2$ Antipsychotic drugs/admission & $12.6 \pm 9.11$ & $9.04 \pm 7.55$ & 1.39 & 3.74 & 0.0002 \\
\hline Age initially $\geq 40$ years & $11.0 \pm 9.21$ & $8.54 \pm 6.66$ & 1.29 & 3.69 & 0.0002 \\
\hline >2 Psychotropic drugs/admission & $11.2 \pm 8.71$ & $8.75 \pm 7.32$ & 1.28 & 3.47 & 0.0006 \\
\hline Psychotic in hospital & $10.1 \pm 8.26$ & $7.81 \pm 6.36$ & 1.29 & 3.22 & 0.001 \\
\hline Suicidal act ever & $10.7 \pm 9.56$ & $8.62 \pm 6.24$ & 1.24 & 3.18 & 0.002 \\
\hline $\mathrm{BMI} \geq 25 \mathrm{~kg} / \mathrm{m}^{2}$ & $10.3 \pm 8.34$ & $8.23 \pm 6.94$ & 1.25 & 3.05 & 0.002 \\
\hline
\end{tabular}

Data are mean \pm SD of annualized costs for psychiatric hospital care over 3 years in $\mathrm{N}=589$ patient-subjects [94.2\% with psychotic or major affective disorder diagnoses] The overall mean cost/year was 9496 [Cl: 8861-10,132] USD]. Factors [ $\mathrm{n}=18]$ are ranked in descending order of significance, based on a Bonferroni adjusted criterion of $p \leq 0.002[0.05 / 21]$ as significant; 16 were not directly related to hospitalization itself. Factors not associated with cost of hospital treatment included: [a] sex, [b] marital status, [c] smoking or substance abuse, [d] suicidal ideation within 6 months, [e] inpatient brain MRI or EEG studies, [f] considered poorly adherent to outpatient treatment, [g] living non-independently prior to hospitalization, and [h] GAF $<30$ at initial admission.

Table 2: Factors associated with total annualized costs of psychiatric inpatient treatment. 


\begin{tabular}{|c|c|c|c|c|}
\hline Rank & Diagnosis & $\begin{array}{c}\text { Subjects } \\
\mathbf{( n )}\end{array}$ & $\begin{array}{c}\text { Total Cost } \\
\mathbf{( \$ / y e a r )}\end{array}$ & $\begin{array}{c}\text { Cost } \\
\mathbf{9 5 \%} \mathbf{C l}\end{array}$ \\
\hline 1 & Schizoaffective & 107 & 20,116 & $1661-23,571$ \\
\hline 2 & Schizophrenia & 77 & 18,125 & $14,151-22,099$ \\
\hline 3 & Bipolar disorder & 174 & 12,584 & $10,884-14,284$ \\
\hline 4 & Major Depressive disorder & 70 & 12,127 & $9447-14,807$ \\
\hline 5 & Other Psychotic disorder & 74 & 10,577 & $8705-12,449$ \\
\hline 6 & Miscellaneous & 34 & 9653 & $5848-13,548$ \\
\hline 7 & Other Mood disorder & 53 & 8092 & $6249-9935$ \\
\hline- & All Subjects & 589 & 13,797 & $12,695-14,899$ \\
\hline
\end{tabular}

Cost is thousands of dollars/year per person.

Table 3: Total cost/person-year versus psychiatric diagnosis.

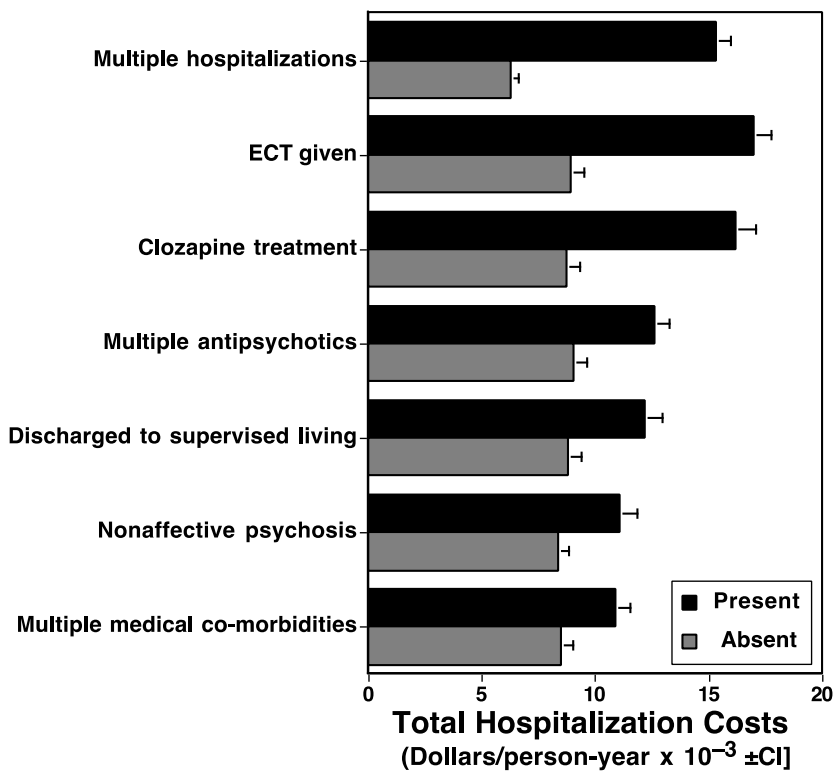

Figure 1: Annual cost of hospital care per person (thousands of dollars $\pm 95 \%$ confidence interval $[\mathrm{Cl}]$ ) with (black bars) versus without (gray bars) the stated factor being present, ranked by difference. All differences are highly statistically significant (all $p<0.0002)$

hospitalizations/year retained as an independent variable, six other significantly associated factors ranked [by $\beta$ with $\mathrm{CI}]$ : [a] treatment with ECT $(\beta=16.0(10.3-21.8))$, [b] treatment with clozapine (12.5 (7.32$17.8)$ ), [c] discharge to a supervised living situation (7.02 (3.22-10.8)), [d] diagnosis of a non-affective or schizoaffective psychotic disorder (3.86 [0.70-7.03]), [e] more specialist consultations in hospital (3.64 (2.16-5.11)), and [f] more antipsychotic drugs/person in hospital (2.73 (1.08-4.38); not shown). As expected, factors associated with overall costs of inpatient care were also correlated with days hospitalized per year.

\section{Discussion}

The present findings are based on assessments of 589 patients diagnosed with a DSM-5 psychotic or major affective disorder, treated and followed at a university-affiliated psychiatric hospital. They confirm that many clinical and administrative factors are associated with, or contribute to overall actual costs of psychiatric inpatient care. As expected, the dominant driver of costs $(>90 \%)$ were per diem changes for hospitalization. In addition, however, 16 factors, not directly related to days hospitalized, also were significantly associated with higher total costs per person-year (Table 2). Notably this included sex, marital status, substance abuse, use of relatively expensive diagnostic tests, suspected poor adherence to previous treatment, and living non-independently. Most factors associated with costs appear to reflect relatively severe or complex illnesses, including treatment with clozapine, multiple antipsychotics, or ECT, specialist-consultations in hospital, having multiple, co-occurring general medical conditions, and receiving multiple non-psychotropic medicines. Diagnostically, patients with a primary, non-affective or schizoaffective psychotic disorder (Table 3) and those with psychotic features in any disorder, as well as suicidal behavior at any time were substantially more costly than subjects lacking such features. More years of lifetime illness, being older, unemployed, or requiring a supervised living situation after discharge also were associated with higher costs of care (Table 2, Figure 1). Notably, too, lower costs were associated with the index hospitalization as a firstlifetime experience; this factor, too, probably reflects differences between subjects with recent, relatively acute illnesses and those with prolonged or recurrent illnesses. This interpretation also accords with striking differences in costs between subjects with chronic, psychotic disorders versus mood disorders (Table 3 ).

In linear multivariate modeling, six factors remained associated independently and significantly with higher costs of hospital care, even with number of hospitalizations/year retained as an independent covariate (Table 4). These included diagnosis of a primary psychotic disorder (schizophrenia or schizoaffective disorder), more specialist consultations, treatment with ECT, clozapine, or multiple antipsychotic drugs, and being discharged to a supervised aftercare facility. Unsurprisingly, the same factors also correlated with days/year hospitalized.

Again, we propose that most of the identified factors reflect more severe and prolonged illnesses that were relatively difficult to treat and required more time in hospital. It is notable, for example, that use of clozapine has been associated with savings in treatment costs in other circumstances notably, in comparisons of similarly severely ill subjects treated with this unusually effective drug versus others [56,57]. Here, however, use of clozapine evidently signals unusually severe and otherwise inadequately treatment-responsive illness.

Although this study considered actual costs rather than insurancereimbursements, the observed costs at the study site were close to reported hospitalization costs of similarly diagnosed (mainly psychotic and bipolar disorder) subjects in other comparable settings $[40,44]$. The estimated total cost of hospital treatment was approximately $\$ 714 /$ day of hospitalization over three years, with an average of 13 days/admission at the study site. These findings compare well with recent estimates of $\$ 793 /$ day in hospital for comparably diagnosed subjects in other settings, during admissions averaging 10 days $[39,40]$. It is reassuring that the estimated total costs at the study site based on actual costs

\begin{tabular}{|l|c|c|c|c|}
\hline Factor & Slope $[\beta]$ & $\mathbf{9 5 \%} \mathbf{C l}$ & t-score & p-value \\
\hline More hospitalizations/year & 15.6 & $14.1-17.1$ & 20.8 & $<0.0001$ \\
\hline More consultations in hospital & 4.37 & $3.07-5.68$ & 6.58 & $<0.0001$ \\
\hline Given ECT & 14.2 & $6.14-19.4$ & 5.48 & $<0.0001$ \\
\hline Given clozapine & 9.51 & $4.88-14.1$ & 4.03 & $<0.0001$ \\
\hline More antipsychotics in hospital & 2.79 & $1.33-4.25$ & 3.75 & $<0.0001$ \\
\hline Supervised living after discharge & 5.84 & $2.48-9.20$ & 3.41 & 0.001 \\
\hline Nonaffective psychosis & 4.04 & $1.25-6.85$ & 2.84 & 0.005 \\
\hline
\end{tabular}

Factors considered are based on findings in Table 1 [factors not included in the model were not significantly associated with cost]; model fit: $F[7 ; 547 \mathrm{df}]=103$, $p<0.00001$. Costs are in thousands of dollars per person per year.

Table 4: Multivariate linear regression model of factors associated with higher costs for psychiatric hospitalization. 
were similar to those estimated on the basis of insurers' reimbursement rates used in other studies of the costs of clinical care $[5,20,43]$. It is also interesting to compare the costs of psychiatric hospitalization to those for common general medical disorders. For example, recent cost-estimates of hospitalization for stroke have averaged 21.8 (CI: 4.70-39.0), and for a heart attack or comparable cardiac illness, 27.3 (8.75-35.8) thousands of US dollars, or 2.3-2.9-times more than the average cost of psychiatric hospitalization at the present study site, 9.50 (8.86-10.1) [58-60].

Many of the cost-associated factors identified appear to be related to longer-lasting or more severe illness, apparent treatment-resistance, and consequent disability. It is plausible that improved long-term treatments and clinical management that can limit acute symptoms as well as long-term morbidity and disability and provide supportive protection can reduce costs of psychiatric hospitalization overall [36,43]. Such a conclusion is hardly surprising, and efforts to improve the care of the severely and chronically mentally ill are a major focus of contemporary psychiatric research and practice. Nevertheless, such efforts should have high priority, with specific attention to both anticipated costsavings and cost-shifting. Less costly alternatives include practicable and well-tested options, such as partial-hospital, day-treatment, group homes, intensive outpatient care, and active community management programs. However, such programs vary widely in their accessibility and support by third-party payers, despite proven to be effective and less costly than hospitalization [36,37,43,61-64].

A major limitation of the present study is that the study sample, though large, only considered severe mental illnesses requiring inpatient care. Additionally, as the sample is from a single institution, it may not fully adequately represent other types of hospitals in other locations, although the costs encountered and lengths of hospitalization were similar to those reported in other recent studies, as noted $[40,44]$. A notable feature of the present analyses is their basis on actual costs rather than on insurer reimbursement rates, as have been used in other studies of costs of psychiatric treatment $[5,20]$.

\section{Conclusion}

Not surprisingly, the present findings indicate that measures consistent with severe, chronic, and treatment-resistant psychotic illnesses were significantly associated with greater costs of inpatient psychiatric treatment, controlling for effects of hospitalization frequency. Specific factors identified encourage focusing on patient characteristics associated with greater costs and redoubled efforts to apply and improve cost-effective alternatives to psychiatric hospitalization.

\section{Acknowledgement}

Supported, in part, by a Psychiatric Research Fellowship from the Sapienza Foundation of the University of Rome and Sant'Andrea Medical Center (to MC), a grant from the Bruce J. Anderson Foundation and by the McLean Private Donors Psychiatric Research Fund (to RJB). Assistance in pricing of services was greatly assisted by senior members of the McLean Hospital accounting and pharmacy departments (Ms. Emily Barr and Stanley Rosen, RPh, MHA).

\section{References}

1. Merikangas KR, Akiskal HS, Angst J, Greenberg PE, Hirschfeld RM, et al. (2007) Lifetime and 12-month prevalence of bipolar spectrum disorder in the National Comorbidity Survey replication. Arch Gen Psychiatry 64: 543-552.

2. Markowitz M, Karve S, Panish J, Candrilli SD, Alphs L (2013) Antipsychotic adherence patterns and health care utilization and costs among patients discharged after a schizophrenia-related hospitalization. BMC Psychiatry 5: 246-259.

3. Karve S, Markowitz M, Fu DJ, Lindenmayer JP, Wang CC, et al. (2014) Assessing medication adherence and healthcare utilization and cost patterns among hospital-discharged patients with schizoaffective disorder. Appl Health Econ Health Policy 12: 335-346

4. Wittchen HU, Jacobi F (2005) Size and burden of mental disorders in Europe-a critical review and appraisal of 27 studies. Eur Neuropsychopharmacol 15 357-376.

5. Mark TL, Levit KR, Coffey RM, McKusick DR, Harwood HJ, et al. (2007) National Expenditures for Mental Health Services and Substance Abuse Treatment, 1993-2003. SAMHSA Publication No. SMA 07-4227. Substance Abuse and Mental Health Services Administration, Rockville, MD.

6. Druss BG, Hwang I, Petukhova M, Sampson NA, Wang PS, et al. (2009) Impairment in role functioning in mental and chronic medical disorders in the United States: results from the National Comorbidity Survey Replication. Mol Psychiatry 14: 728-737.

7. World Health Organization (WHO) (2008) Global Burden of Disease: 2004 Update. WHO Press, Geneva, Switzerland.

8. Kessler RC, Aguilar-Gaxiola S, Alonso J, Chatterji S, Lee S, et al. (2009) The global burden of mental disorders: an update from the WHO World Mental Health (WMH) surveys. Epidemiol Psichiatr Soc 18: 23-33.

9. Ekman M, Granstrom O, Omerov S, Jacob J, Landen M (2013) The societal cost of schizophrenia in Sweden. J Ment Health Policy Econ 16: 13-25.

10. Parker G, McCraw S, Hadzi-Pavlovic D, Fletcher K (2013) Costs of the principal mood disorders: study of comparative direct and indirect costs incurred by those with bipolar I, bipolar II and unipolar disorders. J Affect Disord 149: 46-55

11. Bock JO, Luppa M, Brettschneider C, Riedel-Heller S, Bickel H, et al. (2014) Impact of depression on health care utilization and costs among multimorbid patients--from the MultiCare Cohort Study. PLoS One 9: e91973.

12. Ascher-Svanum H, Zhu B, Faries DE, Salkever D, Slade EP, et al. (2010) The cost of relapse and the predictors of relapse in the treatment of schizophrenia. BMC Psychiatry 10: 2.

13. Blader JC (2011) Acute inpatient care for psychiatric disorders in the United States, 1996 through 2007. Arch Gen Psychiatry 68: 1276-1283.

14. Fok ML, Stewart R, Hayes RD, Moran P (2014) Impact of co-morbid personality disorder on use of psychiatric services and involuntary hospitalization in people with severe mental illness. Soc Psychiatry Psychiatr Epidemiol 49: 1631-1640.

15. Domino ME, Norton EC, Morrissey JP, Thakur N (2004) Cost shifting to jails after a change to managed mental health care. Health Serv Res 39: 1379-1401.

16. Department of Justice (DOJ) (2006) Mental Health Problems of Prison and Jail Inmates (Publication No. NCJ-213600). Bureau of Justice Statistics, US Department of Justice, Washington, DC.

17. Harcourt BE (2007) The mentally ill, behind bars. New York Times.

18. Kuehn BM (2014) Criminal justice becomes front line for mental health care. JAMA 311: 1953-1954.

19. Levit KR, Kassed CA, Coffey RM, Mark TL, McKusick DR, et al. (2008) Projections of National Expenditures for Mental Health Services and Substance Abuse Treatment, 2004-2014. Publication No. SMA 08-4326. US Substance Abuse and Mental Health Services Administration [SAMHSA], Rockville, MD.

20. Starr P (2012) Remedy and Reaction: The Peculiar American Struggle Over Health Care Reform. Yale J Biol Med 85: 159-160.

21. Insel TR (2008) Assessing the economic costs of serious mental illness. Am J Psychiatry 165: 663-665.

22. Insel TR (2011) The economics of mental health care reform.

23. Munro D (2014) Annual US healthcare spending hits $\$ 3.8$ trillion. Forbes Magazine.

24. Masters GA, Baldessarini RJ, Öngür D, Centorrino F (2014) Factors associated with length of psychiatric hospitalization. Compr Psychiatry 55: 681-687.

25. Baldessarini, Ross J (2013) Chemotherapy in Psychiatry, third edition. New York: Springer Press.

26. Baldessarini RJ (2014) The impact of psychopharmacology on contemporary psychiatry. Can J Psychiatry 59: 401-405.

27. Barnett PG, Scott JY, Krystal JH, Rosenheck RA; CSP 555 Research Group (2012) Cost and cost-effectiveness in a randomized trial of long-acting risperidone for schizophrenia. J Clin Psychiatry 73: 696-702. 
28. Lay B, Salize HJ, Dressing H, Rüsch N, Schönenberger T, et al. (2012) Preventing compulsory admission to psychiatric inpatient care through psychoeducation and crisis focused monitoring. BMC Psychiatry 12: 136-146.

29. Cheung D, Roper L, Purdon SE (2014) Pathways to (specialized) care: patient costs and contacts en route to a first-episode psychosis clinic. Early Interv Psychiatry 8: 375-381.

30. Kleinman L, Lowin A, Flood E, Gandhi G, Edgell E, et al. (2003) Costs of bipolar disorder. Pharmacoeconomics 21: 601-622.

31. Klimke A, Bader R, Berton R, Borrmann-Hassenbach M, Brobeil T, et al. (2014) [Reimbursement in psychiatry and psychosomatics: proof of concept for a system based on daily costs]. Nervenarzt 85: 88-95.

32. Niehaus DJ, Koen L, Galal U, Dhansay K, Oosthuizen PP, et al. (2008) Crisis discharges and readmission risk in acute psychiatric male inpatients. BMC Psychiatry 8: 44

33. Johnson S, Lloyd-Evans B, Morant N, Gilburt H, Shepherd G, et al. (2010) Alternatives to standard acute in-patient care in England: roles and populations served. Br J Psychiatry Suppl 53: s6-6s13.

34. Glick ID, Sharfstein SS, Schwartz HI (2011) Inpatient psychiatric care in the 21st century: the need for reform. Psychiatr Serv 62: 206-209.

35. Lichtenberg $P$ (2011) The residential care alternative for the acutely psychotic patient. Psychiatr Q 82: 329-341.

36. Thornicroft G, Essock SM (2012) Community treatment for people with schizophrenia. Chapt 9 in Lieberman JA, Murray RM (Eds), Comprehensive Care of Schizophrenia (second Edn). Oxford University Press, New York 199. 218

37. Vázquez-Bourgon J, Salvador-Carulla L, Vázquez-Barquero JL (2012) Community alternatives to acute inpatient care for severe psychiatric patients. Actas Esp Psiquiatr 40: 323-332.

38. Siskind D, Harris M, Kisely S, Brogan J, Pirkis J, et al. (2013) Retrospective quasi-experimental study of a community crisis house for patients with severe and persistent mental illness. Austral NZ J Psychiatry 47: 667-675.

39. Salkever D, Domino ME, Burns BJ, Santos AB, Deci PA, et al. (1999) Assertive community treatment for people with severe mental illness: the effect on hospital use and costs. Health Serv Res 34: 577-601.

40. Banta JE, Belk I, Newton K, Sherzai A (2010) Inpatient charges and mental illness: Findings from the Nationwide Inpatient Sample 1999-2007. Clinicoecon Outcomes Res 2: 149-158.

41. Centorrino F, Goren JL, Hennen J, Salvatore P, Kelleher JP, et al. (2004) Multiple versus single antipsychotic agents for hospitalized psychiatric patients: case-control study of risks versus benefits. Am J Psychiatry 161: 700-706.

42. Centorrino F, Fogarty KV, Sani G, Salvatore P, Cimbolli P, et al. (2005) Antipsychotic drug use: McLean Hospital, 2002. Hum Psychopharmacol 20: 355-358.

43. Frank RG, Domino ME (2012) Economic factors in the diagnosis and treatment of schizophrenia. Chapt 18 in in Lieberman JA, Murray RM [Eds]. Comprehensive Care of Schizophrenia, second edition. Oxford University Press, New York 393-406.

44. Stensland M, Watson PR, Grazier KL (2012) An examination of costs, charges and payments for inpatient psychiatric treatment in community hospitals. Psychiatr Serv 63: 666-671.

45. Lang K, Federico V, Muser E, Menzin J, Menzin J (2013) Rates and predictors of antipsychotic non-adherence and hospitalization in Medicaid and commerciallyinsured patients with schizophrenia. J Med Econ 16: 997-1006.

46. Lin CH, Chen MC, Chou LS, Lin CH, Chen CC, et al. (2010) Time to rehospitalization in patients with major depression vs. those with schizophrenia or bipolar I disorder in a public psychiatric hospital. Psychiatry Res 180: 74-79.

47. Addington DE, Patten SB, McKenzie E, Addington J (2013) Relationship between relapse and hospitalization in first-episode psychosis. Psychiatr Serv 64: 796-799.

48. Wu DB, Lee EH, Chung WS, Chow DP, Lee VW, et al. (2013) Cost analysis of risperidone long-acting injection in the treatment of schizophrenia and schizoaffective disorders in Hong Kong: an approach using generalized estimating equation. Psychiatry Res 210: 745-750.

49. Chai YK, Wheeler Z, Herbison P, Gale C, Glue P (2013) Factors associated with hospitalization of adult psychiatric patients: cluster analysis. Australas Psychiatry 21: 141-146

50. Mansouri N, Chimeh N, Dehghani M, Malakouti SK, Taherkhani H, et al (2013) Risk factors associated with psychiatric hospitalization among Iranian schizophrenic patients. Iran J Psychiatry Behav Sci 7: 16-23.

51. Olivares JM, Sermon J, Hemels M, Schreiner A (2013) Definitions and drivers of relapse in patients with schizophrenia: a systematic literature review. Ann Gen Psychiatry 12: 32.

52. Sánchez R, Jaramillo LE, Herazo MI (2013) [Factors associated with early psychiatric rehospitalization]. Biomedica 33: 276-282.

53. Jaramillo-Gonzalez LE, Sanchez-Pedraza R, Herazo MI (2014) The frequency of rehospitalization and associated factors in Colombian psychiatric patients: a cohort study. BMC Psychiatry 14: 161

54. Centorrino F, Tami LM, Talamo A, Oh K, Chang J (2009) Health and economic burden of metabolic comorbidity among individuals with bipolar disorder. J Clin Psychopharmacol 29: 595-600.

55. Centorrino F, Masters GA, Talamo A, Baldessarini RJ, Öngür D (2012) Metabolic syndrome in psychiatrically hospitalized patients treated with antipsychotics and other psychotropics. Hum Psychopharmacol 27: 521-526.

56. Nielsen J, Kane JM, Correll CU (2012) Real-world effectiveness of clozapine in patients with bipolar disorder: results from a 2-year mirror-image study. Bipolar Disord 14: 863-869.

57. Wilson WH, Claussen AM (1995) 18-month outcome of clozapine treatment for 100 patients in a state psychiatric hospital. Psychiatr Serv 46: 386-389.

58. Naccarelli GV, Johnston SS, Lin J, Patel PP, Schulman KL (2010) Cost-burden of cardiovascular hospitalization and mortality in ATHENA-like patients with atrial fibrillation/atrial flutter in the United States. Clin Cardiol 33: 270-279.

59. O'Sullivan AK, Rubin J, Nyambose J, Kuznik A, Cohen DJ, et al. (2011) Cost estimation of cardiovascular disease events in the US. Pharmacoeconomics 29: 693-704.

60. Qureshi Al, Adil MM, Zacharatos $H$, Suri MF (2013) Factors associated with length of hospitalization in patients admitted with transient ischemic attack in United States. Stroke 44: 1601-1605.

61. Latimer E (2005) Economic considerations associated with assertive community treatment and support employment for people with severe mental illness. J Psychiatry Neurosci 30: 355-359.

62. Deakin N, Bhugra D (2012) State of psychiatric services in the UK. Int Rev Psychiatry 24: 379-384.

63. Armijo J, Méndez E, Morales R, Schilling S, Castro A, et al. (2013) Efficacy of community treatments for schizophrenia and other psychotic disorders: a literature review. Front Psychiatry 4: 116.

64. Franx G, Dixon L, Wensing M, Pincus H (2013) Implementation strategies for collaborative primary care-mental health models. Curr Opin Psychiatry 26: 502 510 .

Citation: Curto M, Masters GA, Girardi P, Baldessarini RJ, Centorrino F (2016) Factors Associated with Costs of Hospitalization of Severely Mentally III Patients. Bipolar Disord 2: 104. doi:10.4172/jbd.1000104 